\title{
Left ventricular remodeling early after correction of mitral regurgitation: Maintenance of stroke volume with decreased systolic indexes
}

\author{
Elena A. Ashikhmina, MD, ${ }^{\mathrm{a}}$ Hartzell V. Schaff, MD, ${ }^{\mathrm{a}}$ Rakesh M. Suri, MD, DPhil, ${ }^{\mathrm{a}}$ \\ Maurice Enriquez-Sarano, MD, ${ }^{b}$ and Martin D. Abel, MD $^{\mathrm{c}}$
}

\begin{abstract}
Objective: Mitral valve repair for mitral regurgitation is followed by left ventricle adjustment to new preload and afterload. We evaluated left ventricular geometry and function immediately after mitral valve repair for degenerative prolapse.
\end{abstract}

\begin{abstract}
Methods: We prospectively studied 25 patients undergoing mitral valve repair; 15 patients undergoing a coronary artery bypass graft served as controls to determine the impact of cardiopulmonary bypass and cardioplegic arrest on left ventricular function. Intraoperative transesophageal echocardiography was conducted after sternotomy before initiation of cardiopulmonary bypass and after termination of cardiopulmonary bypass and protamine infusion. Simultaneous pulmonary catheter data ensured that the images were obtained under similar hemodynamic conditions.
\end{abstract}

Results: Immediately after mitral valve repair, left ventricular fractional area change decreased significantly from $65 \% \pm 7 \%$ to $52 \% \pm 8 \%(P<.001)$. Left ventricular end-diastolic area decreased minimally $\left(21.3 \pm 5.3 \mathrm{~cm}^{2} \mathrm{vs}\right.$ $\left.19.4 \pm 4.5 \mathrm{~cm}^{2} ; P=.005\right)$, whereas left ventricular end-systolic area increased significantly $\left(7.5 \pm 2.3 \mathrm{~cm}^{2}\right.$ vs 9.3 $\left.\pm 2.5 \mathrm{~cm}^{2} ; P<.001\right)$. Notably, forward stroke volume (thermodilution) remained similar $(63 \pm 24 \mathrm{~mL}$ vs $66 \pm 19$ $\mathrm{mL} ; P=.5$ ). No significant difference was found in controls between pre- cardiopulmonary bypass and post-cardiopulmonary bypass fractional area change $(54 \% \pm 12 \%$ vs $57 \% \pm 10 \% ; P=.19)$, left ventricular end-diastolic area $\left(16.6 \pm 6.2 \mathrm{~cm}^{2}\right.$ vs $\left.15.7 \pm 5.0 \mathrm{~cm}^{2} ; P=.32\right)$, and stroke volume $(72 \pm 29 \mathrm{~mL}$ vs $65 \pm 19 \mathrm{~mL} ; P=.15)$; they had a slight decrease in left ventricular end-systolic area $\left(7.9 \pm 4.4 \mathrm{~cm}^{2}\right.$ vs $\left.6.9 \pm 3.2 \mathrm{~cm}^{2} ; P=.03\right)$.

Conclusions: Early after correction of mitral regurgitation, left ventricular fractional area change decreases significantly, primarily as the result of a larger end-systolic dimension. This may be a compensatory mechanism to prevent augmentation of forward stroke volume after mitral valve repair. (J Thorac Cardiovasc Surg 2010;140:1300-5)

Early after correction of mitral valve (MV) regurgitation, systolic function of the left ventricle (LV) declines, but the underlying mechanisms are unknown. Most studies have analyzed LV function at 1 week postoperatively ${ }^{1-4}$ or later. ${ }^{5-12}$ Although the advantages of MV repair versus replacement have been demonstrated in long-term follow-up, ${ }^{13,14}$ the immediate postoperative changes in LV function after MV repair have not been defined. We examined postoperative changes of LV geometry and assessed LV function immediately after correction of mitral regurgitation (MR) caused by degenerative valve disease (leaflet prolapse).

From the Divisions of Cardiovascular Surgery, ${ }^{\text {a }}$ Cardiovascular Diseases, ${ }^{\text {b }}$ and Cardiovascular and Thoracic Anesthesia, ${ }^{\mathrm{c}}$ Mayo Clinic, Rochester, Minn.

Disclosures: None.

Received for publication July 20, 2009; revisions received Oct 16, 2009; accepted for publication Dec 14, 2009; available ahead of print March 12, 2010.

Address for reprints: Hartzell V. Schaff, MD, Division of Cardiovascular Surgery, Mayo Clinic, 200 First Street SW, Rochester, MN, 55905 (E-mail: schaff@mayo. edu).

$0022-5223 / \$ 36.00$

Copyright (C) 2010 by The American Association for Thoracic Surgery doi:10.1016/j.jtcvs.2009.12.031

\section{MATERIALS AND METHODS}

After institutional review board approval, we prospectively studied 25 patients undergoing MV repair for degenerative leaflet prolapse and 15 patients undergoing coronary artery bypass grafting (CABG). The 15 patients who underwent $\mathrm{CABG}$ served as controls for estimation of the possible impact of cardiopulmonary bypass (CPB) and cardioplegic arrest on LV function. Operations were performed with normothermic $\mathrm{CPB}$ and hypothermic antegrade blood cardioplegia for myocardial protection.

Transesophageal echocardiography (TEE) with simultaneous SwanGanz catheter hemodynamic measurements was performed after sternotomy before initiation of $\mathrm{CPB}$ (pre-CPB) and after termination of $\mathrm{CPB}$ and 10 to 15 minutes after protamine infusion (post-CPB).

LV size and function were measured off-line. Technical difficulties in obtaining a nonforeshortened LV cavity from the esophageal approach for quantification of $\mathrm{LV}$ volumes by TEE sometimes produced inconsistent results similar to those described previously. ${ }^{15}$ Schmidlin and colleagues ${ }^{16}$ demonstrated good correlation between intraoperative LV area measurements with TEE and conductance catheter LV volume measurements. Thus, we chose to evaluate more reproducible LV linear dimensions and plane areas from the transgastric mid-papillary view that correlate well with LV volumes. The largest (end-diastole) and smallest (end-systole) frames were identified by subjective assessment of cavity size and confirmed with electrocardiographic systole and diastole. The greatest distances between 2 endocardial borders of the anterior and inferior $\mathrm{LV}$ walls were measured (LV end-diastolic dimension [LVEDD] and end-systolic dimension [LVESD]), and LV areas were traced (LV end-diastolic area [LVEDA] 


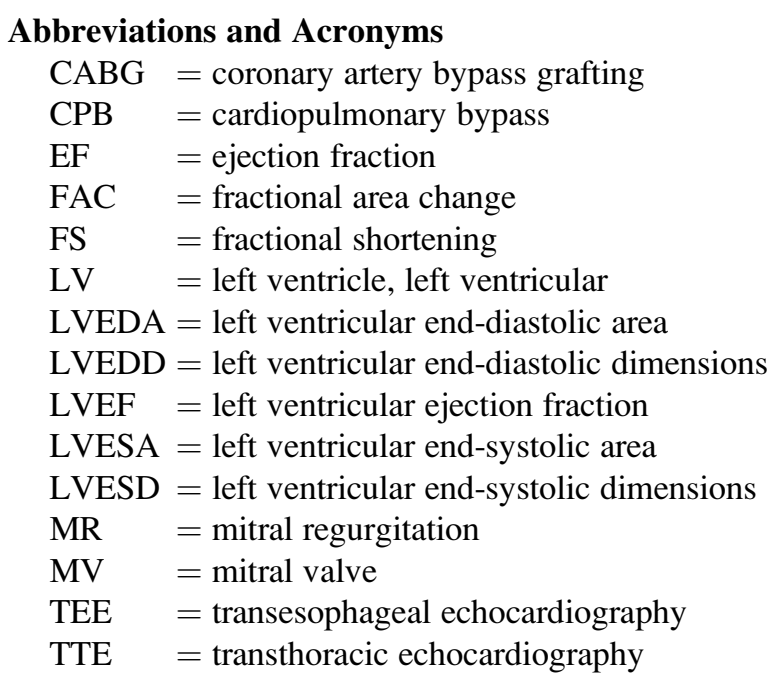

and end-systolic area [LVESA]); the average values of 3 representative cardiac cycles were then recorded. Fractional area change (FAC), a conventional systolic phase index of LV function, ${ }^{17}$ correlates well with LV ejection fraction $(\mathrm{EF}) .{ }^{18}$ It was calculated as FAC $=[($ LVEDA-LVESA $) /$ LVEDA] $\times 100 \%, \mathrm{~cm}^{2} .{ }^{15}$

While echocardiographic images were being recorded, we performed hemodynamic measurements with a pulmonary catheter to ensure that they were obtained under similar preoperative and postoperative ventricular loading conditions (pulmonary capillary wedge pressure, $13.9 \pm 4.9 \mathrm{~mm}$ $\mathrm{Hg}$ vs $13.0 \pm 2.3 \mathrm{~mm} \mathrm{Hg}[P=.45]$, and right atrial pressure, $6.9 \pm 3.3$ $\mathrm{mm} \mathrm{Hg}$ vs $7.3 \pm 3.0 \mathrm{~mm} \mathrm{Hg}[P=.2]$, in MV repair group; pulmonary capillary wedge pressure, $14.6 \pm 5.2 \mathrm{~mm} \mathrm{Hg}$ vs $14.3 \pm 5.1 \mathrm{~mm} \mathrm{Hg}[P=.88]$, and right atrial pressure, $9.2 \pm 4.5 \mathrm{~mm} \mathrm{Hg}$ vs $8.7 \pm 3.8 \mathrm{~mm} \mathrm{Hg}[P=.7]$, in controls). Tricuspid regurgitation assessed semiquantitatively was absent or trivial in all 40 patients; thus, hemodynamic measurements were affected minimally. No patient received inotropic medication before or after CPB.

MR volume was estimated by calculating the proximal isovelocity surface area of the regurgitant jet.

Descriptive statistics for categoric variables are reported as frequency and percentage; continuous variables are reported as mean \pm standard deviation. Categoric variables were compared between cases and controls using the chi-square test. When appropriate, continuous variables were compared using the 2-sample $t$ test or the Wilcoxon rank-sum test. Changes in categoric variables over time were compared using the McNemar test, and changes in continuous variables were compared using the paired $t$ test or rank-sum test. All statistical tests were 2-sided.

\section{RESULTS}

Both groups contained more men than women (Table 1). Patients undergoing MV repair were younger than controls. Preoperatively, most patients undergoing MV repair (84\%) had mild symptoms (New York Heart Association class I or II), whereas patients from the CABG group had more severe functional limitations $(73 \%$ New York Heart Association class III). Durations of CPB and aortic crossclamping were significantly shorter for MV repair than for CABG $(P<.001)$.

The most common pathologic finding in the 25 patients who underwent MV repair was posterior leaflet prolapse
(92\%), typically of the middle scallop, caused by elongation or rupture of chordae tendineae; 11 (44\%) of 25 patients had associated anterior leaflet prolapse. Sixteen patients $(64 \%)$ underwent partial triangular resection and suture repair of the posterior leaflet with insertion of a standard-length (63$\mathrm{mm}$ ) flexible posterior annuloplasty band. Two patients $(8 \%)$ had suture closure of the cleft between scallops of the anterior leaflet with insertion of an annuloplasty band. Seven patients (28\%) had MV repair with a posterior annuloplasty band without leaflet repair. The average MR volume was $73 \pm 25 \mathrm{~mL}$. Patients undergoing CABG received an average of 3 bypass grafts; none had MR.

\section{Immediate Changes of Left Ventricular Geometry After Mitral Valve Repair}

After MV repair, considerable changes in LV size and function were observed with intraoperative TEE shortly after reconstruction (Table 2). LV chamber size decreased slightly at end diastole and increased prominently at end systole (Figure 1). As a result, postoperative versus preoperative fractional shortening (FS) and FAC declined significantly $(P<.001)$ (Figure 2$)$.

Patients undergoing CABG had more heterogeneous echocardiographic data than did patients with MV repair (Figures 1 and 2). In the CABG group $(\mathrm{N}=15)$, FAC increased after CPB in 4 patients $(27 \%)$ and decreased in 2 patients $(13 \%)$. Overall, the average FAC in the CABG group did not change (Table 2). LVESD and LVESA decreased slightly.

LV forward stroke volume in patients with MV repair remained normal and was unchanged compared with pre-CPB values. Both groups had an increased heart rate early after CPB (Table 2). Thus, cardiac output and index were slightly increased after MV repair (Table 2). Among patients undergoing CABG, postbypass stroke volumes were also similar to prebypass values; cardiac output and index were slightly higher but not statistically significant compared with prebypass measurements (Table 2).

\section{Early Changes of Left Ventricular Geometry After Mitral Valve Repair}

To further evaluate early postoperative changes in LV size and function after MV repair, we analyzed preoperative (admission) and postoperative (predismissal) transthoracic echocardiograms (TTEs) of the 25 patients with MV repair. TTE was performed an average of $4 \pm 1$ days after surgery. LVEDD decreased from $5.7 \pm 0.6 \mathrm{~cm}$ preoperatively to 5.2 $\pm 0.4 \mathrm{~cm}$ postoperatively $(P<.001)$, but LVESD was basically unchanged $(3.7 \pm 0.7 \mathrm{~cm}$ before vs $3.6 \pm 0.5 \mathrm{~cm}$ after surgery; $P=.41)$. LVEF declined significantly $(64 \% \pm 6 \%$ vs $57 \% \pm 9 \%$ postoperatively; $P<.001)$. There was no difference in mean blood pressure from preoperative to postoperative evaluations $(83 \pm 8 \mathrm{~mm} \mathrm{Hg}$ vs $85 \pm 7 \mathrm{~mm} \mathrm{Hg} ; P=$ $.44)$, but heart rate was higher postoperatively ( $71 \pm 18$ vs 
TABLE 1. Baseline characteristics of patients*

\begin{tabular}{lccc}
\hline \multicolumn{1}{c}{ Variable } & MV repair $(\mathbf{N}=\mathbf{2 5})$ & CABG $(\mathbf{N}=\mathbf{1 5})$ & $\boldsymbol{P}$ value \\
\hline Age, mean \pm SD, y & $53 \pm 12$ & $67 \pm 12$ & .002 \\
Male patients, no. $(\%)$ & $17(68)$ & $10(67)$ & $>.99$ \\
Body mass index & $25.3 \pm 3.3$ & $33.3 \pm 6.4$ & $<.001$ \\
NYHA class & & & \\
I & $12(48)$ & None & .001 \\
II & $9(36)$ & $3(20)$ & .48 \\
III & $4(16)$ & $11(73)$ & $<.001$ \\
IV & None & $1(7)$ & .38 \\
Type of prolapse & & & \\
Anterior leaflet & $2(8)$ & None & NA \\
Posterior leaflet & $12(48)$ & None & NA \\
Bileaflet & $11(44)$ & None & NA \\
Grafts, no. & None & $3 \pm 0.6$ & NA \\
CPB time, min & $39 \pm 14$ & $78 \pm 25$ & $<.001$ \\
Crossclamp time, min & $28 \pm 11$ & $56 \pm 16$ & $<.001$ \\
& & & \\
\hline
\end{tabular}

$\overline{C A B G \text {, Coronary artery bypass graft; } C P B \text {, cardiopulmonary bypass; } M V \text {, mitral }}$ valve; $N A$, not applicable; $N Y H A$, New York Heart Association; $S D$, standard deviation. *Values are mean \pm standard deviation unless indicated otherwise.

$82 \pm 13 ; P=.010)$. Cardiac output by TTE and calculated cardiac index increased after MV repair $(6.3 \pm 2.6 \mathrm{~L} / \mathrm{min}$ vs $7.4 \pm 1.9 \mathrm{~L} / \mathrm{min}$ and $3.2 \pm 1.3 \mathrm{~L} / \mathrm{min} / \mathrm{m}^{2}$ vs $3.8 \pm 0.8 \mathrm{~L} / \mathrm{min} /$ $\mathrm{m}^{2}$, whereas LV stroke volume remained normal $(92 \pm 23$ $\mathrm{mL}$ vs $85 \pm 20 \mathrm{~mL} ; P=.31$ ).

\section{DISCUSSION}

Our findings demonstrate that LV geometry and systolic function change immediately after surgical repair of MR for MV prolapse. Notably, calculated indexes of global systolic function (in this study, FS and FAC) decreased after surgery, primarily because of increased LV end-systolic size. However, hemodynamic parameters, including cardiac output and forward stroke volume, were maintained, which suggests preservation of cardiac pump function. The control patients undergoing CABG, who had cardioplegic arrest similar to or longer than that of the patients undergoing MV repair, exhibited no change in postoperative LV systolic function and hemodynamics except for increased heart rate. Our data suggest that immediately after MR correction, volumetric adjustments in the LV ensure constant forward stroke volume at the expense of decreased EF (or FAC). This remodeling or adjustment of the ventricle cannot be explained by myocardial injury related to CPB or cardioplegic arrest.

LVEF decline after MR correction is a common clinical observation that may persist postoperatively. One explanation is that correction of MR increases LV afterload and "unmasks" underlying LV dysfunction. In a retrospective study, Enriquez-Sarano and colleagues ${ }^{5}$ reported LVEF decline from $62 \%$ to $52 \%(P<.001)$ in 217 patients with organic MR within the first year after MV replacement or repair. This decline was due to decreased LVEDD and minimal change in LVESD.
Several investigators have reported that MV repair may have an early hemodynamic advantage over MV replacement. Bonchek and colleagues ${ }^{10}$ analyzed preoperative and postoperative ventriculograms and found minimal change in LVEF 1 week after MV repair (66\% vs $62 \% ; P$ $=$ not significant). Corin and colleagues ${ }^{11}$ reported a decline in LVEF after MV replacement from $60 \%$ to $48 \%(P<.01)$, but preserved LVEF after MV repair (64\% vs $61 \% ; P=$ not significant). By using TTE, Kouris and colleagues ${ }^{12}$ observed similar changes in postoperative EF.

A few reports have addressed ventricular remodeling within the first few weeks after surgery. ${ }^{1-3}$ After valve repair for MR, Moreo and colleagues ${ }^{1}$ described decreased LVEF and decreased LVEDD at a mean follow-up of $9 \pm 3$ days. Similarly, Leung and colleagues ${ }^{2}$ found an LVEF decline 8 \pm 14 days after MV repair. These results correspond to the most recent data reported by Suri and colleagues ${ }^{3}$ for 861 patients who had MR correction; 779 patients (90\%) had MV repair. At an average interval of 5 days postoperatively, LVEF declined from $63 \%$ to $53 \%(P<.001)$ and LVEDD decreased from 70 to $53 \mathrm{~mm}(P<.001)$; postoperative LVESD remained similar to preoperative LVESD. Our current study had findings similar to those of Suri and colleagues ${ }^{3}$ in that after MV repair, patients had decreased LVEF and LVEDD but unchanged LVESD at $4 \pm 1$ days postoperatively.

The very early intraoperative phases of remodeling were not assessed in these studies. Dubroff and colleagues ${ }^{19}$ used intraoperative epicardial echocardiography to assess LV changes in 5 different groups, including patients who had valve replacement for MR. They reported an LVEF decline immediately after CPB $(49 \%$ vs $32 \% ; P<.02)$, accompanied by slight increases in LVEDA and LVESA. In patients undergoing CABG, postoperative LVEF remained unchanged ( $48 \%$ vs $49 \% ; P=$ not significant). Our findings using contemporary TEE methods are similar, but our patients had MV repair versus replacement.

Early postoperative measurements of cardiac geometry and function may be confounded by the effects of global ischemia, reperfusion, and myocardial protection. Cardiac loading conditions also change dramatically early after operation. ${ }^{19-21}$ To evaluate the possible impact of global ischemia on myocardial function, we included the control group undergoing $\mathrm{CABG}$. These patients had no significant differences in FAC or diastolic/systolic size of the LV preoperatively and postoperatively, despite longer durations of CPB compared with patients who had MV repairs $(P<$ $.001)$. Thus, in routine cases with contemporary cardioprotection, there is little attendant myocardial injury, which cannot account for the decline in ejection phase indexes of patients having MR valve repair. Moreover, the decline in LV FAC after MV repair cannot be explained by different filling pressure because prebypass and postbypass parameters were recorded under the same right atrial pressure and pulmonary capillary wedge pressure. 
TABLE 2. Intraoperative echocardiographic changes and hemodynamic data before and after mitral valve repair/coronary artery bypass graft*

\begin{tabular}{|c|c|c|c|}
\hline Variable & Pre-CPB & Post-CPB & $P$ value \\
\hline \multicolumn{4}{|c|}{ Echocardiographic changes } \\
\hline \multicolumn{4}{|c|}{ LVEDD, $\mathrm{cm}$} \\
\hline MV & $5.4 \pm 0.7$ & $5.2 \pm 0.6$ & .08 \\
\hline CABG & $4.7 \pm 1.0$ & $4.5 \pm 0.8$ & .4 \\
\hline \multicolumn{4}{|l|}{ LVESD, $\mathrm{cm}$} \\
\hline MV & $3.2 \pm 0.6$ & $3.6 \pm 0.5$ & $<.001$ \\
\hline CABG & $3.1 \pm 0.9$ & $2.9 \pm 0.8$ & .02 \\
\hline \multicolumn{4}{|l|}{ LVEDA, $\mathrm{cm}^{2}$} \\
\hline MV & $21.3 \pm 5.3$ & $19.4 \pm 4.5$ & .005 \\
\hline CABG & $16.6 \pm 6.2$ & $15.7 \pm 5.0$ & .32 \\
\hline \multicolumn{4}{|l|}{ LVESA, $\mathrm{cm}^{2}$} \\
\hline MV & $7.5 \pm 2.3$ & $9.3 \pm 2.5$ & $<.001$ \\
\hline CABG & $7.9 \pm 4.4$ & $6.9 \pm 3.2$ & .03 \\
\hline \multicolumn{4}{|l|}{$\mathrm{FS}, \%$} \\
\hline MV & $40 \pm 8$ & $31 \pm 7$ & $<.001$ \\
\hline CABG & $35 \pm 10$ & $36 \pm 10$ & .59 \\
\hline \multicolumn{4}{|l|}{ FAC, $\%$} \\
\hline MV & $65 \pm 7$ & $52 \pm 8$ & $<.001$ \\
\hline CABG & $54 \pm 12$ & $57 \pm 10$ & .19 \\
\hline \multicolumn{4}{|l|}{ Hemodynamic data } \\
\hline \multicolumn{4}{|c|}{ Heart rate, beats/min } \\
\hline MV & $85 \pm 13$ & $92 \pm 9$ & .03 \\
\hline CABG & $70 \pm 10$ & $90 \pm 11$ & $<.001$ \\
\hline \multicolumn{4}{|l|}{ Rhythm, no. (\%) } \\
\hline \multicolumn{4}{|l|}{ Sinus } \\
\hline MV & $24(96)$ & $16(64)$ & .005 \\
\hline CABG & $14(93)$ & $12(80)$ & .32 \\
\hline \multicolumn{4}{|l|}{ Atrial fibrillation } \\
\hline MV & $1(4)$ & $0(0) \dagger$ & NA \\
\hline CABG & $1(7)$ & $0(0) \dagger$ & NA \\
\hline \multicolumn{4}{|l|}{ Atrial pacing } \\
\hline MV & $0(0)$ & $9(36)$ & NA \\
\hline CABG & $0(0)$ & $3(20)$ & NA \\
\hline \multicolumn{4}{|c|}{ Blood pressure, $\mathrm{mm} \mathrm{Hg}$} \\
\hline \multicolumn{4}{|l|}{ Systolic } \\
\hline MV & $105 \pm 17$ & $104 \pm 13$ & .77 \\
\hline CABG & $114 \pm 16$ & $103 \pm 18$ & .25 \\
\hline \multicolumn{4}{|l|}{ Diastolic } \\
\hline MV & $60 \pm 10$ & $62 \pm 8$ & .4 \\
\hline CABG & $64 \pm 7$ & $57 \pm 10$ & .07 \\
\hline \multicolumn{4}{|l|}{$\mathrm{PAP}, \mathrm{mm} \mathrm{Hg}$} \\
\hline \multicolumn{4}{|l|}{ Systolic } \\
\hline MV & $27 \pm 8$ & $23 \pm 5$ & .04 \\
\hline CABG & $28 \pm 8$ & $28 \pm 8$ & .82 \\
\hline \multicolumn{4}{|l|}{ Diastolic } \\
\hline MV & $14 \pm 5$ & $12 \pm 3$ & .08 \\
\hline CABG & $14 \pm 6$ & $15 \pm 5$ & .72 \\
\hline \multicolumn{4}{|l|}{$\mathrm{RAP}, \mathrm{mm} \mathrm{Hg}$} \\
\hline MV & $7 \pm 3$ & $7 \pm 3$ & .2 \\
\hline CABG & $9 \pm 4$ & $9 \pm 4$ & .7 \\
\hline PCWP, mm Hg & & & \\
\hline
\end{tabular}

TABLE 2. Continued

\begin{tabular}{|c|c|c|c|}
\hline Variable & Pre-CPB & Post-CPB & $P$ valu \\
\hline MV & $14 \pm 5$ & $13 \pm 2$ & .45 \\
\hline CABG & $15 \pm 5$ & $14 \pm 5$ & .88 \\
\hline \multicolumn{4}{|l|}{$\mathrm{CO}, \mathrm{L} / \mathrm{min}$} \\
\hline MV & $5.2 \pm 1.9$ & $5.9 \pm 1.8$ & .04 \\
\hline CABG & $5.0 \pm 2.2$ & $5.7 \pm 1.6$ & .12 \\
\hline \multicolumn{4}{|l|}{$\mathrm{CI}, \mathrm{L} / \mathrm{min} / \mathrm{m}^{2}$} \\
\hline MV & $2.6 \pm 0.8$ & $3.0 \pm 0.7$ & .02 \\
\hline CABG & $2.4 \pm 0.8$ & $2.7 \pm 0.5$ & .24 \\
\hline \multicolumn{4}{|l|}{$\mathrm{SV}, \mathrm{mL}$} \\
\hline MV & $63 \pm 24$ & $66 \pm 19$ & .5 \\
\hline CABG & $72 \pm 29$ & $65 \pm 19$ & .15 \\
\hline \multicolumn{4}{|l|}{$\mathrm{SVI}, \mathrm{mL} / \mathrm{m}^{2}$} \\
\hline MV & $31 \pm 10$ & $33 \pm 8$ & .44 \\
\hline CABG & $34 \pm 11$ & $31 \pm 7$ & .38 \\
\hline \multicolumn{4}{|l|}{ SVR, dynes $\cdot \mathrm{s} / \mathrm{cm}^{5}$} \\
\hline MV & $1166 \pm 601$ & $932 \pm 337$ & .04 \\
\hline CABG & $1345 \pm 591$ & $997 \pm 474$ & .03 \\
\hline \multicolumn{4}{|c|}{ SVRI, dynes $\cdot \mathrm{s} / \mathrm{cm}^{5} / \mathrm{m}^{2}$} \\
\hline MV & $2116 \pm 886$ & $1812 \pm 551$ & .15 \\
\hline CABG & $2563 \pm 807$ & $1912 \pm 790$ & .07 \\
\hline \multicolumn{4}{|l|}{ PVR, dynes $\cdot \mathrm{s} / \mathrm{cm}^{5}$} \\
\hline MV & $84 \pm 41$ & $75 \pm 40$ & .42 \\
\hline CABG & $116 \pm 57$ & $224 \pm 77$ & .2 \\
\hline \multicolumn{4}{|c|}{ PVRI, dynes $\cdot \mathrm{s} / \mathrm{cm}^{5} / \mathrm{m}^{2}$} \\
\hline MV & $163 \pm 701$ & $143 \pm 76$ & .45 \\
\hline CABG & $96 \pm 80$ & $183 \pm 124$ & .28 \\
\hline
\end{tabular}

$C A B G$, Coronary artery bypass graft; $C I$, cardiac index; $C O$, cardiac output; $C P B$, cardiopulmonary bypass; $F A C$, fractional area change; $F S$, fractional shortening; $L V$, left ventricle or left ventricular; $L V E D A$, left ventricular end-diastolic area; $L V E D D$, left ventricular end-diastolic dimension; LVESA, left ventricular end-systolic area; $L V E S D$, left ventricular end-systolic dimension; $M V$, mitral valve; $N A$, not available; $P A P$, pulmonary artery pressure; $P C W P$, pulmonary capillary wedge pressure; $P V R$, pulmonary vascular resistance; $P V R I$, pulmonary vascular resistance index; $R A P$, right atrial pressure; $S V$, stroke volume; $S V I$, stroke volume index; $S V R$, systemic vascular resistance; $S V R I$, systemic vascular resistance index. ${ }^{*} \mathrm{~N}=25$ for $\mathrm{MV}$ repair; $\mathrm{N}=15$ for CABG. Values are mean \pm standard deviation unless indicated otherwise. $\dagger P$ value was not calculated if the number of events was equal to zero.

Previously, we speculated that a postoperative decline in LV systolic indexes (eg, EF, FAC, and FS) may be interpreted as a volumetric adjustment of the heart to the correction of MR rather than as postoperative LV dysfunction caused by impaired myocardial contractility. ${ }^{3}$ Our current findings support this hypothesis and are qualitatively similar to those of Dubroff and colleagues. ${ }^{19}$ We hypothesize that soon after MV repair, the LV remodels gradually. Very early after MR correction, the LVESD increases, preventing an acute increase in forward stroke volume. Within the next few postoperative days, the LVEDD begins to decrease and the LVESD changes accordingly to maintain a normal forward stroke volume; the remodeling occurs when neurohumoral mechanisms of the body adapt to the new hemodynamic milieu. This progression of remodeling may explain why some investigators have observed unchanged LV 

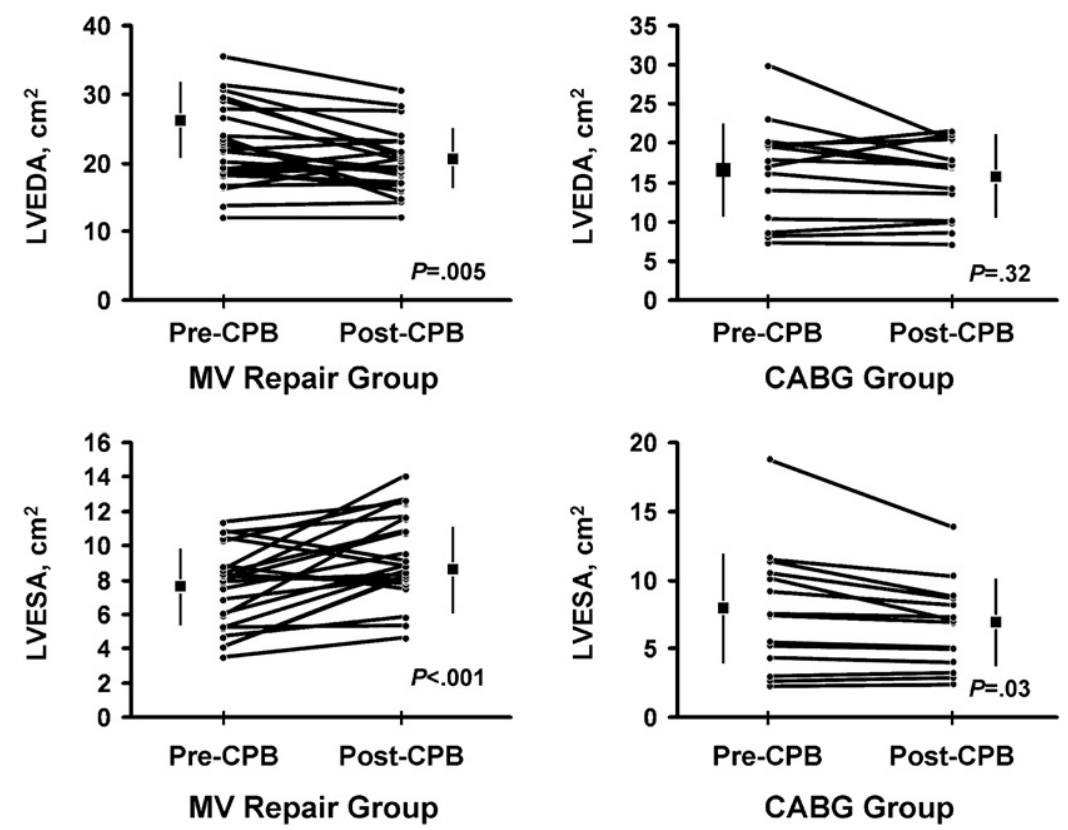

FIGURE 1. LVEDA and LVESA in MV repair and CABG groups. Pre-CPB measurements were performed after sternotomy before initiation of CPB; post$\mathrm{CPB}$ measurements were performed after termination of $\mathrm{CPB}$ and protamine infusion. $L V E D A$, Left ventricular end-diastolic area; $C P B$, cardiopulmonary bypass; $M V$, mitral valve; $C A B G$, coronary artery bypass grafting; $L V E S A$, left ventricular end-systolic area.

systolic and decreased diastolic size on the first postoperative echocardiogram approximately 1 week postoperatively. ${ }^{1-3}$ The sympathetic nervous system has been shown to be activated in patients who have chronic MR. ${ }^{22}$ Unfortunately, there are few data addressing neurohumoral changes that occur early after MR correction; nonetheless, such perturbations have been shown to be related to changes in LV systolic size and systolic performance. ${ }^{23}$

Ideally, early changes in LV function after MR correction should be evaluated by load-independent parameters. Haque
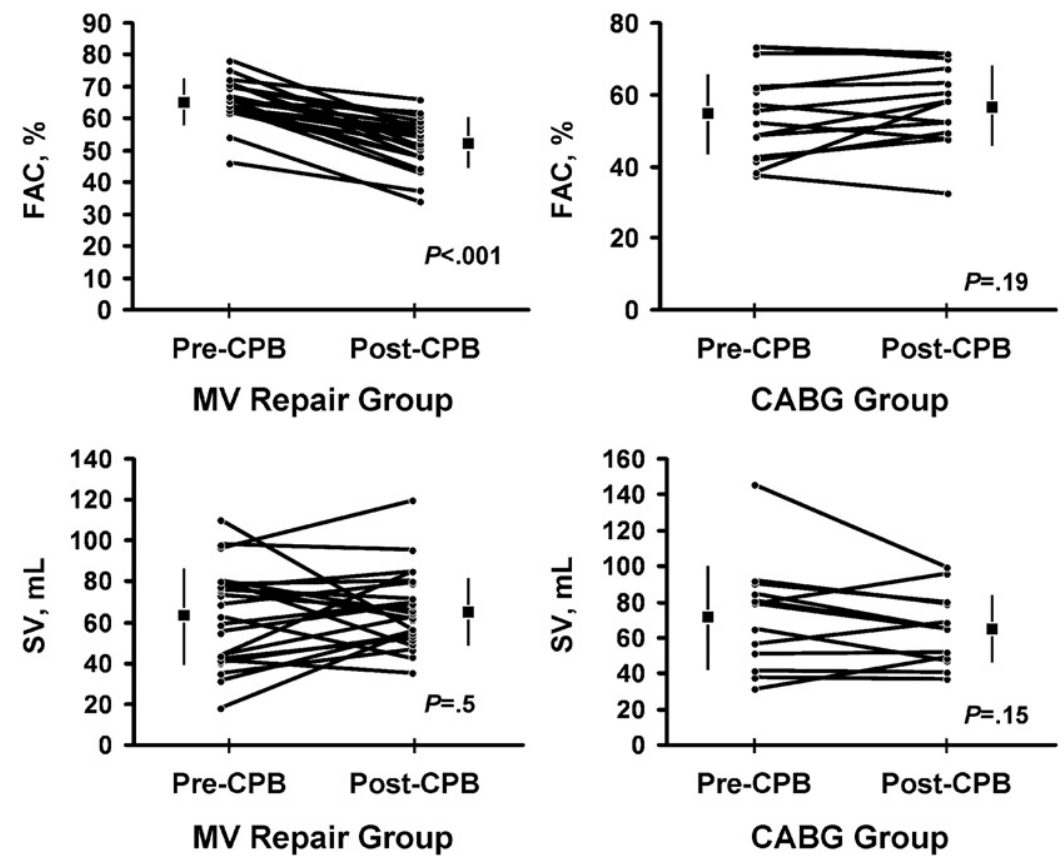

FIGURE 2. LV FAC and stroke volume in MV repair and CABG groups. Note decline of FAC after MV repair and preserved forwarded SV. Pre-CPB measurements were performed after sternotomy before initiation of $\mathrm{CPB}$; post-CPB measurements were performed after termination of $\mathrm{CPB}$ and protamine infusion. $F A C$, Fractional area change; $S V$, stroke volume; $C P B$, cardiopulmonary bypass; $M V$, mitral valve; $C A B G$, coronary artery bypass grafting. 
and colleagues ${ }^{24}$ reported that the Tei index, a relatively load-independent index of myocardial contractility, did not change after MR correction. Similarly, Mabrouk-Zerguini and colleagues ${ }^{25}$ demonstrated that immediately after MV repair, despite the significant FAC decrease from 53\% to $42 \%(P<.001)$, the Tei index was preserved and might predict postoperative FAC. However, the most important conclusion reported by Mabrouk-Zerguini and colleagues is that myocardial contractility reflected by the Tei index remained preserved after MV repair; this corresponds well with our finding of preserved cardiac output.

\section{Limitations}

Although we consider decreased global systolic contractility indexes physiologic, reflecting an adaptation of the body to the correction of MR, decreased EF after MV repair may indicate poor myocardial performance in patients with long-standing MR and preoperative LV dysfunction. In such cases we would expect impairment in indexes of cardiac performance (eg, cardiac output and forward stroke volume), which was not the case for our 25 patients. All patients underwent surgery at a relatively early phase in the disease, and preoperative EF was preserved $(\geq 51 \%)$. No conclusions can be drawn about postoperative LV changes in patients with severely decreased systolic function.

Different sensitivity of methods may lead to discrepancies between the outcomes of TTE and TEE measurements. In addition, general anesthesia, which reduces systemic vascular resistance, may alter LV dimensions estimated by intraoperative TEE compared with those derived by preoperative TTE. We therefore avoided comparing TEE data with TTE data.

\section{CONCLUSIONS}

Immediately after interruption of the pathologic blood flow into the left atrium by MV repair, the heart undergoes volumetric adjustments to ensure constant forward stroke volume at the expense of decreased LV systolic indexes (eg, FAC and EF). This phenomenon cannot be explained by myocardial injury related to $\mathrm{CPB}$ and cardioplegic arrest.

\section{References}

1. Moreo A, Gordini V, Ciliberto GR, Parolini M, Russo C, Pellegrini A. Left ventricular performance in chronic mitral regurgitation: temporal response to valve repair and prognostic value of early postoperative echocardiographic parameters. Ital Heart J. 2000;1:122-7.

2. Leung DY, Griffin BP, Stewart WJ, Cosgrove DM 3rd, Thomas JD, Marwick TH. Left ventricular function after valve repair for chronic mitral regurgitation: predictive value of preoperative assessment of contractile reserve by exercise echocardiography. J Am Coll Cardiol. 1996;28:1198-205.

3. Suri RM, Schaff HV, Dearani JA, Sundt TM 3rd, Daly RC, Mullany CJ, et al. Determinants of early decline in ejection fraction after surgical correction of mitral regurgitation. J Thorac Cardiovasc Surg. 2008;136:442-7.

4. Rozich JD, Carabello BA, Usher BW, Kratz JM, Bell AE, Zile MR. Mitral valve replacement with and without chordal preservation in patients with chronic mitral regurgitation: mechanisms for differences in postoperative ejection performance. Circulation. 1992;86:1718-26.
5. Enriquez-Sarano M, Tajik AJ, Schaff HV, Orszulak TA, McGoon MD, Bailey KR, et al. Echocardiographic prediction of left ventricular function after correction of mitral regurgitation: results and clinical implications. J Am Coll Cardiol. 1994;24:1536-43.

6. Goldfine H, Aurigemma GP, Zile MR, Gaasch WH. Left ventricular length-forceshortening relations before and after surgical correction of chronic mitral regurgitation. J Am Coll Cardiol. 1998;31:180-5.

7. Yun KL, Sintek CF, Miller DC, Pfeffer TA, Kochamba GS, Khonsari S, et al. Randomized trial comparing partial versus complete chordal-sparing mitral valve replacement: effects on left ventricular volume and function. J Thorac Cardiovasc Surg. 2002;123:707-14.

8. Hennein HA, Swain JA, McIntosh CL, Bonow RO, Stone CD, Clark RE. Comparative assessment of chordal preservation versus chordal resection during mitral valve replacement. J Thorac Cardiovasc Surg. 1990;99:828-36.

9. Chowdhury UK, Kumar AS, Airan B, Mittal D, Subramaniam KG, Prakash R, et al. Mitral valve replacement with and without chordal preservation in a rheumatic population: serial echocardiographic assessment of left ventricular size and function. Ann Thorac Surg. 2005;79:1926-33.

10. Bonchek LI, Olinger GN, Siegel R, Tresch DD, Keelan MH Jr. Left ventricular performance after mitral reconstruction for mitral regurgitation. J Thorac Cardiovasc Surg. 1984;88:122-7.

11. Corin WJ, Sutsch G, Murakami T, Krogmann ON, Turina M, Hess OM. Left ventricular function in chronic mitral regurgitation: preoperative and postoperative comparison. J Am Coll Cardiol. 1995;25:113-21.

12. Kouris N, Ikonomidis I, Kontogianni D, Smith P, Nihoyannopoulos P. Mitral valve repair versus replacement for isolated non-ischemic mitral regurgitation in patients with preoperative left ventricular dysfunction: a long-term follow-up echocardiography study. Eur J Echocardiogr. 2005;6:435-42.

13. Schaff HV, Suri RM, Enriquez-Sarano M. Indications for surgery in degenerative mitral valve disease. Semin Thorac Cardiovasc Surg. 2007;19:97-102.

14. Suri RM, Schaff HV, Dearani JA, Sundt TM 3rd, Daly RC, Mullany CJ, et al. Survival advantage and improved durability of mitral repair for leaflet prolapse subsets in the current era. Ann Thorac Surg. 2006;82:819-26.

15. Sivarajan M. Systolic left ventricular function. In: Sidebotham D, Merry A, Legget M, eds. Practical Perioperative Transoesophageal Echocardiography. New York: Butterworth-Heinemann; 2003:101-15.

16. Schmidlin D, Aschkenasy S, Vogt PR, Schmidli J, Jenni R, Schmid ER. Left ventricular pressure-area relations as assessed by transoesophageal echocardiographic automated border detection: comparison with conductance catheter technique in cardiac surgical patients. Br J Anaesth. 2000;85:379-88.

17. Shanewise JS, Cheung AT, Aronson S, Stewart WJ, Weiss RL, Mark JB, et al. ASE/ SCA guidelines for performing a comprehensive intraoperative multiplane transesophageal echocardiography examination: recommendations of the American Society of Echocardiography Council for Intraoperative Echocardiography and the Society of Cardiovascular Anesthesiologists Task Force for Certification in Perioperative Transesophageal Echocardiography. Anesth Analg. 1999;89:870-84.

18. Domanski MJ, Colleran JA, Cunnion RE, Nanda NC. Correlation of echocardiographic fractional area change with radionuclide left ventricular ejection fraction. Echocardiography. 1995;12:221-7.

19. Dubroff JM, Clark MB, Wong CY, Spotnitz AJ, Collins RH, Spotnitz HM. Left ventricular ejection fraction during cardiac surgery: a two-dimensional echocardiographic study. Circulation. 1983;68:95-103.

20. Aybek T, Kahn MF, Dogan S, Abdel-Rahman U, Mierdl S, Kessler P, et al. Cardiopulmonary bypass impairs left ventricular function determined by conductance catheter measurement. Thorac Cardiovasc Surg. 2003;51:301-5.

21. Pasque MK. Mathematic modeling and cardiac surgery. $J$ Thorac Cardiovasc Surg. 2002;123:617-20.

22. Mehta RH, Supiano MA, Grossman PM, Oral H, Montgomery DG, Briesmiester KA, et al. Changes in systemic sympathetic nervous system activity after mitral valve surgery and their relationship to changes in left ventricular size and systolic performance in patients with mitral regurgitation. Am Heart J. 2004;147:729-35.

23. Mehta RH, Supiano MA, Oral H, Grossman PM, Petrusha JA, Montgomery DG et al. Relation of systemic sympathetic nervous system activation to echocardiographic left ventricular size and performance and its implications in patients with mitral regurgitation. Am J Cardiol. 2000;86:1193-7.

24. Haque A, Otsuji Y, Yoshifuku S, Kumanohoso T, Zhang H, Kisanuki A, et al. Effects of valve dysfunction on Doppler Tei index. J Am Soc Echocardiogr. 2002 15:877-83.

25. Mabrouk-Zerguini N, Leger P, Aubert S, Ray R, Leprince P, Riou B, et al. Tei index to assess perioperative left ventricular systolic function in patients undergoing mitral valve repair. Br J Anaesth. 2008;101:479-85. 